\title{
Assessing the impact of varying levels of case detection and contact tracing on COVID-19 transmission in Canada during lifting of restrictive closures using a dynamic compartmental model
}

Antoinette Ludwig ${ }^{1 *}$, Philippe Berthiaume ${ }^{1}$, Heather Orpana ${ }^{2,3}$, Claude Nadeau 4 , Maikol Diasparra ${ }^{4}$ Joel Barnes ${ }^{4}$, Deirdre Hennessy ${ }^{4,5}$, Ainsley Otten ${ }^{4,6}$, Nicholas Ogden ${ }^{1}$

\begin{abstract}
Background: The coronavirus disease 2019 (COVID-19) pandemic began with a detected cluster of pneumonia cases in Wuhan, China in December 2019. Endemic transmission was recognized in Canada in early February 2020, making it urgent for public health stakeholders to have access to robust and reliable tools to support decision-making for epidemic management. The objectives of this paper are to present one of these tools-an aged-stratified dynamic compartmental model developed by the Public Health Agency of Canada in collaboration with Statistics Canada-and to model the impact of non-pharmaceutical interventions on the attack rate of COVID-19 infection in Canada.
\end{abstract}

Methods: This model simulates the impact of different levels of non-pharmaceutical interventions, including case detection/isolation, contact tracing/quarantine and changes in the level of physical distancing in Canada, as restrictive closures began to be lifted in May 2020.

Results: This model allows us to highlight the importance of a relatively high level of detection and isolation of cases, as well as tracing and quarantine of individuals in contact with those cases, in order to avoid a resurgence of the epidemic in Canada as restrictive closures are lifted. Some level of physical distancing by the public will also likely need to be maintained.

Conclusion: This study underlines the importance of a cautious approach to lifting restrictive closures in this second phase of the epidemic. This approach includes efforts by public health to identify cases and trace contacts, and to encourage Canadians to get tested if they are at risk of having been infected and to maintain physical distancing in public areas.
This work is licensed under a Creative Commons Attribution 4.0 International License.

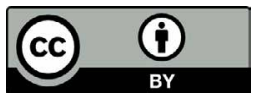

Affiliations

1 Public Health Risk Sciences Division, Public Health Agency of Canada, St-Hyacinthe, OC

${ }^{2}$ Centre for Surveillance and Applied Research, Public Health Agency of Canada, Ottawa, ON

${ }^{3}$ School of Epidemiology and Public Health, University of Ottawa, Ottawa, ON

${ }^{4}$ Health Analysis Division, Statistics Canada, Ottawa, ON

${ }^{5}$ Department of Community Health Sciences, University of Calgary, Calgary, AB

${ }^{6}$ Public Health Risk Sciences Division, Public Health Agency of Canada, Guelph, ON

\section{${ }^{\star}$ Correspondence:}

antoinette.ludwig@canada.ca

Suggested citation: Ludwig A, Berthiaume P, Orpana H, Nadeau C, Diasparra M, Barnes J, Hennessy D, Otten A, Ogden N. Assessing the impact of varying levels of case detection and contact tracing on COVID-19 transmission in Canada during lifting of restrictive closures using a dynamic compartmental model. Can Commun Dis Rep 2020;46(11/12):409-21. https://doi.org/10.14745/ccdr.v46i1112a08

Keywords: COVID-19, case detection, contact tracing, dynamic compartmental model, Canada

\section{Introduction}

The coronavirus disease 2019 (COVID-19) pandemic is a global health threat on a scale that was not seen in a century. The first cases of a cluster of pneumonia in Wuhan, China were reported to the World Health Organization (WHO) on December 31, 2019 with the cause of the outbreak identified as a novel coronavirus (now called severe acute respiratory syndrome coronavirus 2; SARS-CoV-2) on January 7, 2020 (1). Cases were soon detected outside China, with the first case of COVID-19 identified in Canada on January 25, 2020 in a resident who had returned from
Wuhan, China $(2,3)$. As of September 16, 2020, there have been 28.6 million confirmed cases of COVID-19, and over 900,000 deaths, globally (4); within Canada, there have been 139,747 confirmed cases and 9,193 deaths (3).

A number of researchers have developed dynamic models of COVID-19 transmission to explore the effects of public health interventions for Canadian jurisdictions, including in Ontario (5-7) and British Columbia (similar findings have been 
found in personal communications, Anderson et al. Estimating the impact of COVID-19 control measures using a Bayesian model of physical distancing. medRxiv 2020), while many provinces and territories have released the results of COVID-19 modelling (8-12). Given the observed variation in the risk of severe outcomes of COVID-19 by age $(13,14)$, and the need to consider differences in contact and transmission rates amongst age groups $(15,16)$, age stratification is an important consideration for dynamic models of COVID-19. As of early July 2020, only a minority of the models for Canada or its provinces presented in the peer-reviewed or pre-print literature are age-structured (similar findings can be found in personal communications, Tuite et al. Reduced COVID-19-Related Critical Illness and Death, and High Risk of Epidemic Resurgence, After Physical Distancing in Ontario, Canada. medRxiv 2020).

In Canada, public health intervention strategies including physical (social) distancing, case detection and isolation, contact tracing and quarantine of contacts, among others $(16,17)$ have been implemented with the aim of slowing the spread of the epidemic, reducing peak health care demand, reducing the possibility of infection for those most at risk of severe outcomes of the disease and reducing the overall number of deaths (18). In order to implement and optimize effective interventions, decision-makers in Canada need information on the relative impact of these measures. They also need to assess scenarios for lifting restrictive closures (e.g. stay-at-home orders, workplace, school and university closures, which may have severe economic and non-COVID-19 health impacts), while avoiding resurgence of the epidemic (often termed a "second wave") in a Canadian population that remains largely naïve to this infection.

The objectives of this paper are 1) to present an aged-stratified dynamic compartmental model developed by the Public Health Agency of Canada in collaboration with Statistics Canada and 2) to model the impact of non-pharmaceutical interventions (NPIs) including case detection/isolation, contact tracing/quarantine and changes in the level of physical distancing associated with lifting restrictive closures, on the attack rate of COVID-19 infection in Canada.

\section{Simulations of the epidemic}

\section{Model presentation}

An age-stratified dynamic deterministic compartmental model using the susceptible, exposed, infected, removed framework, was developed and applied to the Canadian population stratified into six age groups. Model states are presented in Figure 1. Transmission between individuals can occur within or between age groups at rates influenced by the daily contact number, based on the matrix projected for Canada by Prem et al. (19). Individuals in quarantine were assumed to interact with a maximum of one person daily during the course of the quarantine. As the model aimed to explore the epidemic over a short time period (730 days), the model had a closed

Figure 1: Diagram of the states and flows of the model

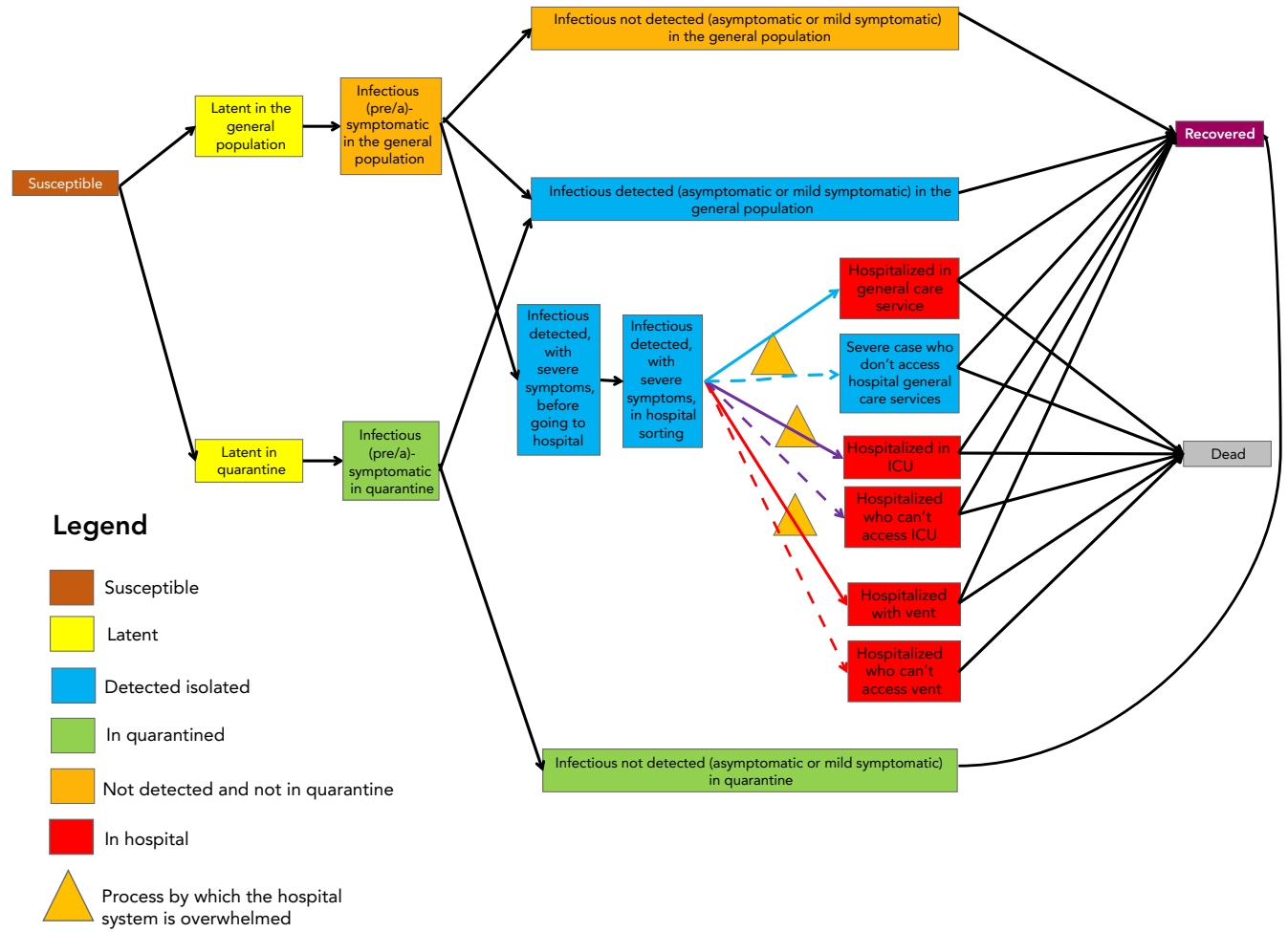

Abbreviation: ICU, intensive care unit

The susceptible state is the brown box; yellow boxes are latent infection states, blue boxes are detected and isolated case states; green boxes are quarantined contact states; orange boxes are

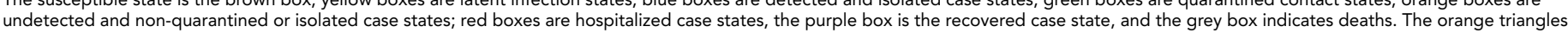
indicate processes by which hospital systems may be overwhelmed if the need for hospital services exceeds available resources 
population with no births or non-COVID-19 related deaths, with a population comprising susceptible people at the beginning of the epidemic. Cases who recovered were assumed not to be susceptible to re-infection during the time period of the model (730 days). The model also assumed the infectivity of presymptomatic infectious individuals who become symptomatic was the same as that of symptomatic individuals, as well as individuals who remained asymptomatic throughout the course of infection. Assuming that all detected cases went into isolation, so case detection was a proxy for isolation (see Table 1). See Appendix A for a description of population flows in the model. While the model includes compartments for hospitalizations, intensive care unit (ICU) admissions, those in ICU on ventilators, and deaths, here are the results of the model for number of cases only. Model equations can be found in Appendix B.

Table 1: Variation of the attack rate (at day 730) for different levels of case detection/isolation, contact tracing/quarantining and physical distancing, after day 88, May 4, 2020

\begin{tabular}{|c|c|c|c|c|c|c|}
\hline \multirow{2}{*}{$\begin{array}{c}\text { Case } \\
\text { detection/ } \\
\text { isolation }\end{array}$} & \multicolumn{6}{|c|}{ Contact tracing and quarantine } \\
\hline & 0.30 & 0.40 & 0.50 & 0.60 & 0.70 & 0.80 \\
\hline \multicolumn{7}{|c|}{ Contact rate reduced by $50 \%$ after day 88} \\
\hline 0.30 & 53.57 & 51.68 & 49.66 & 47.49 & 45.15 & 42.62 \\
\hline 0.40 & 44.21 & 41.06 & 37.61 & 33.84 & 29.71 & 25.24 \\
\hline 0.50 & 31.92 & 27.10 & 21.86 & 16.35 & 11.09 & $7.06^{\mathrm{a}}$ \\
\hline 0.60 & 16.46 & 10.82 & $6.61^{\mathrm{a}}$ & $4.34^{\mathrm{a}}$ & $3.25^{\mathrm{a}}$ & $2.66^{a}$ \\
\hline 0.70 & $4.69^{\mathrm{a}}$ & $3.35^{\mathrm{a}}$ & $2.68^{a}$ & $2.29^{a}$ & $2.05^{\mathrm{a}}$ & $1.88^{\mathrm{a}}$ \\
\hline 0.80 & $2.33^{a}$ & $2.06^{a}$ & $1.88^{a}$ & $1.75^{\mathrm{a}}$ & $1.65^{\mathrm{a}}$ & $1.58^{\mathrm{a}}$ \\
\hline \multicolumn{7}{|c|}{ Contact rate reduced by $33 \%$ after day 88} \\
\hline 0.30 & 68.68 & 67.41 & 66.04 & 64.56 & 62.95 & 61.20 \\
\hline 0.40 & 62.54 & 60.37 & 57.95 & 55.26 & 52.24 & 48.84 \\
\hline 0.50 & 54.22 & 50.68 & 46.65 & 42.02 & 36.70 & 30.61 \\
\hline 0.60 & 42.70 & 37.17 & 30.77 & 23.49 & 15.67 & $8.86^{\mathrm{a}}$ \\
\hline 0.70 & 26.68 & 18.89 & 11.18 & $6.02^{\mathrm{a}}$ & $3.82^{\mathrm{a}}$ & $2.88^{a}$ \\
\hline 0.80 & $8.34^{\mathrm{a}}$ & $4.69^{a}$ & $3.23^{a}$ & $2.56^{a}$ & $2.19^{\mathrm{a}}$ & $1.96^{\mathrm{a}}$ \\
\hline \multicolumn{7}{|c|}{ Contact rate reduced by $16.7 \%$ after day 88} \\
\hline 0.30 & 76.56 & 75.65 & 74.66 & 73.58 & 72.41 & 71.13 \\
\hline 0.40 & 72.20 & 70.63 & 68.87 & 66.89 & 64.66 & 62.13 \\
\hline 0.50 & 66.27 & 63.67 & 60.67 & 57.19 & 53.10 & 48.29 \\
\hline 0.60 & 57.92 & 53.73 & 48.74 & 42.77 & 35.59 & 27.03 \\
\hline 0.70 & 45.80 & 39.18 & 31.21 & 21.85 & 12.20 & $6.03^{a}$ \\
\hline 0.80 & 27.95 & 18.53 & $9.65^{a}$ & $4.96^{a}$ & $3.28^{a}$ & $2.57^{a}$ \\
\hline
\end{tabular}

${ }^{a}$ Scenarios where epidemic control maintained attack rate below $10 \%$ (green)

\section{Parameterization and initialization of model}

Assuming that the first community transmission of SARS-CoV-2 in Canada was February 8, 2020. The simulations were run for the entire Canadian population ( $N=37,894,799$ inhabitants), stratified in six age groups as shown in Appendix A Table S1 and Table S2 $(19,20)$.

Parameter values were set according to observed data for Canada (when available) and values in the literature (see Table S2 in Appendix A), obtained in a scan of the COVID-19 literature (published and pre-published) conducted daily by the Public Health Agency of Canada. Searches to retrieve relevant COVID-19 literature were conducted in Pubmed, Scopus, BioRxiv, MedRxiv, ArXiv, SSRN, Research Square and cross-referenced with the literature on the WHO COVID-19 literature list, and COVID-19 information centers run by Lancet, BMJ, Elsevier and Wiley. Literature with relevant prioritized outcomes were identified from the daily scan and parameter values were recorded in a data-extraction form. Model parameters are reassessed weekly according to new research. The choice of the literature source was made according to the relevance and quality of the publication. Estimates were chosen to reflect the most likely value based on minimum and maximum estimates from studies identified from the literature scanning process, using geography, date of study, sample size and target population as criteria in the choice of the retained literature. Estimates from Canada or similar countries, those with more recent study dates, larger sample sizes and more representative samples were prioritized.

A simple calibration of the probability of successful transmission (beta) of SARS-CoV-2 from an infectious person to an uninfected person when they make contact was obtained (Figure 2). This was achieved through iterative trials that compared a target curve based on reported cases from February 8 to May 4, 2020 (21), and simulation results for the same period. The target curve was obtained from increasing the observed count by $25 \%$ (assuming later in the epidemic reported cases underestimate the actual number by $25 \%$ : personal communication, Dougherty et al., September 15, 2020), and moving the entire curve to be one week earlier (assuming each case was reported one week later than symptom onset). The number of reported cases in the target curve and the number of simulated cases were compared visually to ensure that the parameter values for the simulations were reasonable before assessing the impacts of NPIs.

Initial values for each model state were set according to the number of cases reported in Canada at February 8, 2020, which was seven cases. The epidemic was initiated with 10 latent individuals, 20 presymptomatic individuals and two individuals with mild symptoms in the general population. The values were chosen to be higher than the observed number of cases to reflect both likely underdetection of cases, as well as the lag between the moment of exposure and the detection and declaration of cases. All other model state variables were set to zero. 
Figure 2: Comparison of observed cases in Canada from February 8 (day 1) to May 4, 2020 (day 88)

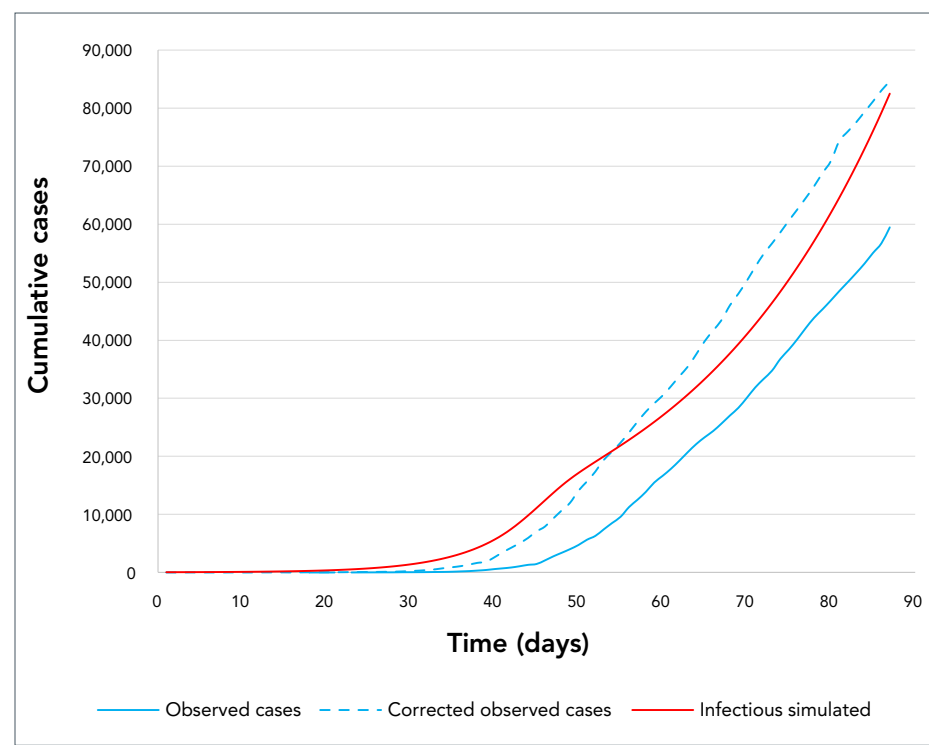

Corrected cases (assuming one week of delay between infection end detection, and a level of underreporting of $25 \%$ ) corresponding to the target curve, and simulated cumulative infectious cases with the age-stratified model

The model was implemented in R using RStudio, using the following packages: adaptivetau; deSolve; dplyr; DT; forcats; ggplot2; htmlwidgets; Ihs; magrittr; openxlsx; plotly; readxl; scales; tidyr; and triangle. Code is available upon request to the authors.

No ethics approval was required as all data were based on surveillance reports publically available from the Public Health Agency of Canada and published literature sources.

\section{Simulations of non-pharmaceutical interventions}

A total of 108 possible epidemics were simulated to assess the impact of different levels of case detection/isolation and contact tracing/quarantine under three scenarios for different levels of contact rates due to changes in physical distancing following de-escalation of restrictive closures as of May 4, 2020 (day 88). The study design is represented in Figure 3. From day 0 until day 88 , all three scenarios are identical and involved constant levels of case detection/isolation (a conservative $40 \%$ of cases detected) and contact tracing/quarantine (40\% traced and quarantined) while physical distancing (and thus the contact rates) varied according to the following: 1) an initial period of 40 days during which the level of daily contacts corresponded to what is normally observed in the general population; 2) a seven-day period during which the daily contact rate was gradually reduced by $50 \%$ to represent the implementation of physical distancing associated with the start of implementation of restrictive closures in Canada; and 3) a period of 40 days (from day 47 to day 87) over which physical distancing due to the restrictive closures maintained contact rates at $50 \%$ below pre-COVID-19 levels.
Figure 3: Simulation study design showing initial period of epidemic (before day 88)

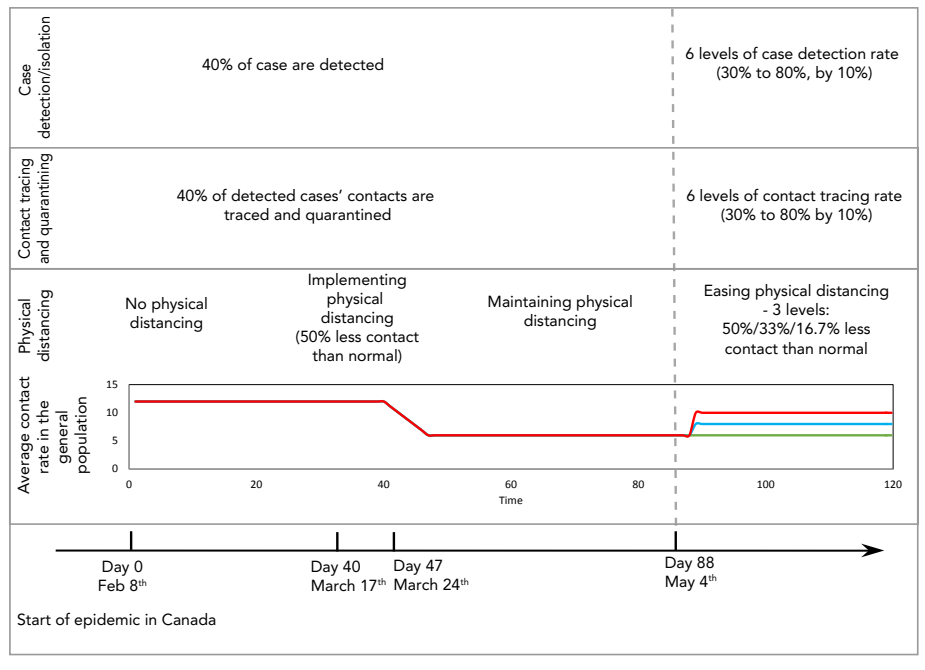

During implementation of, and while maintaining physical distancing, along with a consistent leve of case detection/isolation and contact tracing/quarantine; and second period of epidemic (after day 88 ) with varying levels of physical distancing (red at $16.7 \%$, blue at $33 \%$ and green at $50 \%$ less contact than normal), case detection and contact tracing

From day 88 (the date of lifting restrictive closures), there were three scenarios for physical distancing: 1) physical distancing was kept such that contact rates remained $50 \%$ less than pre-COVID-19 levels (i.e. restrictive closures are not lifted); while in 2) and 3) restrictive closure were lifted to allow contact rates to increase, respectively, to $33 \%$ or $16.7 \%$ below pre-COVID-19 levels until the end of the simulation. Six levels of case detection/isolation (from $30 \%$ to $80 \%$ in $10 \%$ increments) and six levels of contact tracing/quarantine (from $30 \%$ to $80 \%$ by $10 \%$ increments) were simulated for each one of the three scenarios of physical distancing, for a total of 108 simulated epidemics.

\section{Outcome measures}

The attack rate was the primary outcome of the simulation experiments, consisting of the cumulative number of infected people over the entire initial population, for the entire 730 days of the epidemic, or at the end of the simulation period if the epidemic was not completed. Simulations longer than two years were considered as unrealistic given the assumption that recovered individuals do not return to the susceptible state during the simulation. Currently, there is not enough scientific evidence to confirm post-infection immunity in all recovered cases, or the duration of immunity any individual may achieve from a COVID-19 infection (22-24). Attack rates below $10 \%$ were considered corresponded to a condition of "epidemic control" of COVID-19 in Canada, below which the healthcare system was less likely to be overwhelmed.

A analysis of sensity of the attack rate to an increase or decrease of the transmission coefficient (beta) by $10 \%$ (using the formula Sensitivity $=((\mathrm{Vi}-\mathrm{VO}) / \mathrm{VO}) /(\mid(\mathrm{Ti}-\mathrm{TO}) / \mathrm{TO})$ ) (25) was performed, where $\mathrm{VO}$ is the attack rate without changes to input data [TO] and Vi is the attack rate with a given increase or decrease of input [Ti]). 


\section{Outcomes}

Attack rates of the 108 simulations are presented in Table 1 and illustrated in Figure 4; both table and figure show how the attack rate reduction evolved according to the different levels of NPI. Results showed that relaxing physical distancing at day 88 (40 days after its implementation) had a significant impact on the attack rate in all the simulated epidemics, with the attack rate varying between $1.6 \%$ and $76.6 \%$. The extent of the impact of the easing of physical distancing varied according to the values of the other control measures already in place; i.e. the case detection/isolation rate and the contact tracing/quarantine rate. An attack rate below $10 \%$, which was considered here to represent epidemic control, was much more frequent when the contact rate was kept at $50 \%$ level below normal after day 88 , compared with lower levels of physical distancing.

\section{Figure 4: Simulation of the epidemic for three scenarios} after day 88, May 4, 2020

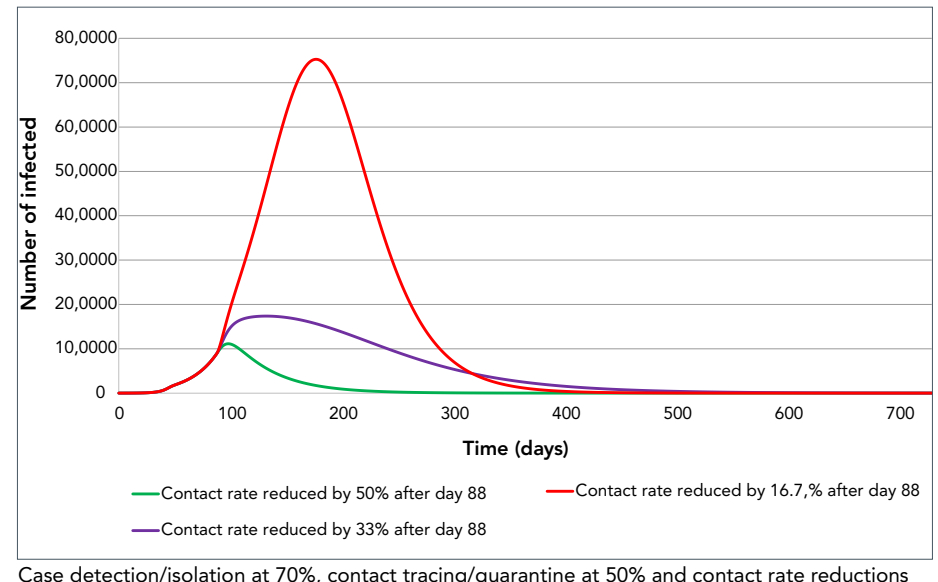
of $50 \%, 33 \%$ or $16.7 \%$ below pre-pandemic levels. Values for days before 88 are described in

Figure 3. The y-axis includes all individuals in the infectious states-presymptomatic, symptomatic (hospitalized or not) and asymptomatic

Additionally, a level of case detection/isolation of $70 \%$ or more allowed for control of the simulated epidemics at all levels of contact tracing above $30 \%$ when physical distancing is maintained at $50 \%$ below normal levels. However, the level of case detection and contact tracing needed to control the epidemic increased markedly if physical distancing was not maintained to reduce contact rates.

The results also suggest that the relative impact of case detection/isolation on the decrease of the attack rate appeared to be higher than that of contact tracing. Even with contact tracing at levels as high as $80 \%, 50 \%$ of cases had to be detected to control the epidemic when physical distancing kept contact rates $50 \%$ lower than pre-COVID-19 levels. An even higher level of case detection was required when physical distancing was lifted to allow contact rates to rise to $16.7 \%$ or $33 \%$ below pre-COVID-19 levels.
The sensitivity analysis for beta showed that the average percent change for the attack rate was lower than $10 \%$ in most scenarios, increasing with increasing beta $(8.1 \%$; $S D=9.2 \%$; data not shown) and decreasing with decreasing beta (4.1\%; SD=2.9\%). When beta was increased, the number of combinations of case detection and contact tracing rates resulting in an attack rate less than $10 \%$ reduced by half (from 32 to 16) while decreasing beta resulted in an increase (from 32 to 43 ) in the number of combinations resulting in an attack rate less than $10 \%$ (see Appendix C).

\section{Discussion}

\section{Summary of key findings}

This work highlights, in order of importance, that ensuring a relatively high level of detection/isolation of cases and tracing/ quarantine of potentially infected cases while maintaining some personal physical distancing will all be necessary to avoid a resurgence of the epidemic in Canada.

\section{Comparison with other studies}

These results are in accordance with an example presented in Ogden et al. (26), based on a deterministic compartmental model that was not age stratified. Additionally, similar studies that assessed the impact of NPIs for Canada as a whole, or for a specific Canadian province, have come to similar conclusions $(5,27,28)$ (similar findings have been found in personal communication, Tuite et al. Reduced COVID-19-Related Critical IIIness and Death, and High Risk of Epidemic Resurgence, After Physical Distancing in Ontario, Canada. medRxiv 2020 and in Eastman et al. Mathematical modeling of COVID-19 containment strategies with considerations for limited medical resources. medRxiv. 2020). Even if a direct comparison between results in different studies is difficult because of differences in details of the modelling study design (study region, epidemic start date, inclusion or not of stochasticity and epidemic outbreak metric), they all concluded that control of the epidemic requires a combination of three things: 1) maintenance of some level of physical distancing (for a minimum of 10 months according to Tuite et al. (5)); 2) enhanced detection of cases; and 3) tracing and quarantine of contacts, to minimize the attack rate.

\section{Strengths and limitations}

A major strength of this study is that it provides a clear signal of the potential impact of lifting restrictive closures (represented in this study by release of physical distancing), which began in many jurisdictions within Canada around mid-May 2020. The results of the simulation experiments presented here demonstrated that during the lifting restrictive closures, public health decision-makers and practitioners will need to maintain continued vigilance to avoid the resurgence of the COVID-19 epidemic (a "second wave"), through the maintenance of a high level of case detection and contact tracing and some level of physical distancing. A further strength of this work is that the 
chosen model states are comprehensive and account for the main disease statuses, including latent and presymptomatic states. Additionally, the model accounts for the age structure in the Canadian population, which is an important element of transmission risk heterogeneity (29). Finally, modeling the case detection level instead of the ratio of asymptomatic cases has allowed to circumvent the difficulty of obtaining precise information on the number of asymptomatic cases, which is a still a challenge for COVID-19 modelling.

A limitation of this study, which applies to most mathematical modelling work, is that translating the levels of NPI modelled into the real world is not always easy for the public health stakeholders and can be open to interpretation. In this study, we used our current best estimates for parameter values; however, these values may change as knowledge of COVID-19 increases. The preliminary sensitivity analysis that was conducted shows that the results were relatively robust to changes in beta (the transmission coefficient); therefore, the attack rate values obtained here should be considered as illustrative of the principle that increased case detection and contact tracing, as well as maintenance of some physical distancing, will be needed to control the epidemic as restrictive closures are lifted.

Additionally, the model does not account for delays between onset of symptoms and case detection or between case detection and contact tracing/quarantining. It is recognized that these delays exist and have been reported elsewhere in the world (30). In the United States and the United Kingdom, it has been shown that these delays are subject to significant variation depending on the study population, the strength of symptoms and the vulnerability of the person, though no published estimates of these delays are yet available for Canada (Personal communication, Lawless et al. Estimation of Symptomatic Case Counts and the COVID-19 Infection Curve Through Reporting Delay Adjustment: An Observational Study of Ontario Surveillance).

Finally, the contact matrices used are the result of projections for Canada based on data from other countries in Europe and corrected for socio-demographic and health factors (19). Actual contact rate data for Canada would strengthen future versions of this model.

\section{Implications and next steps}

his study underlines the importance of a cautious approach to lifting restrictive closures. It appears that maintaining some level of physical distancing (for example, by limitations on the size of gatherings, maintaining a two metre distance, or maintaining a social bubble) or other non-pharmaceutical measures (such as wearing non-medical masks) combined with high levels of case detection and contact tracing are key components of epidemic control. It this context, it seems important to support strategies aimed at encouraging people to get tested when they may have been exposed to suspected or confirmed COVID-19 cases, encouraging people to respect isolation instructions as well as strategies that support personal protection measures, such as mandating the use of non-medical masks in indoor public settings (31), in order to offset the risk of infection from the increase of physical proximity of citizens that comes with re-opening.

\section{Conclusion}

This paper presents an aged-stratified dynamic compartmental model for the transmission of COVID-19 in Canada. As well, these results provide estimates of the impact of NPIs, including case detection/isolation, contact tracing/quarantine and changes in the level of physical distancing, on the COVID-19 attack rate, for a period of time after mid-May 2020, when lifting of restrictive closures began at a national level. The model and analyzed scenarios demonstrate that case detection/isolation and contact tracing/quarantine, along with reduced rates of contact through some form of physical distancing, will be essential for future control of the COVID-19 epidemic.

\section{Authors' statement}

$\mathrm{AL}, \mathrm{PB}$ and $\mathrm{NO}$ - Conceptualization

$\mathrm{AL}, \mathrm{PB}, \mathrm{AO}, \mathrm{HO}$ - Data curation (parameter values)

$A L, P B, C N, D H, J B, M D$ - Analysis

$A L, P B, H O$ - Writing-original draft

$A L, P B, N O, A O, H O, C N, D E, J B, M D$ - Writing-review and editing

$\mathrm{NO}$ - Supervision

$A L, P B$ - Contributed equally to this work

\section{Competing interests}

None.

\section{Acknowledgements}

The authors would like to thank the Knowledge Synthesis team members within Public Health Risk Sciences Division of Public Health Agency of Canada. Their daily literature scans and summarization of SARS-CoV-2 publications contributed to the quick preparation of the work presented here.

\section{Funding}

This work was supported by the Public Health Agency of Canada. 


\section{References}

1. World Health Organization. Novel coronavirus (2019-nCov) Weekly Epidemiological Update and Weekly Operational Update. September 14, 2020 Weekly Epidemiological Update. Geneva (Switzerland): WHO; 2020.

https://www.who.int/docs/default-source/coronaviruse/ situation-reports/20200914-weekly-epi-update-5.pdf?sfvrsn= cf929d04_2\&download=true

2. Silverstein WK, Stroud L, Cleghorn GE, Leis JA. First imported case of 2019 novel coronavirus in Canada, presenting as mild pneumonia. Lancet 2020;395(10225):734. DOI PubMed

3. Public Health Agency of Canada. Coronavirus disease (COVID-19): Outbreak update. Ottawa (ON): PHAC; 2020 (accessed 2020-09-16). https://www.canada.ca/en/ public-health/services/diseases/2019-novel-coronavirusinfection.html

4. World Health Organization. Coronavirus disease (COVID-19): situation report,111. Geneva (Switzerland): WHO; 2020. https://www.who.int/docs/default-source/ coronaviruse/situation-reports/20200510covid-19-sitrep-111. pdf?sfvrsn=1896976f_6

5. Tuite AR, Fisman DN, Greer AL. Mathematical modelling of COVID-19 transmission and mitigation strategies in the population of Ontario, Canada. CMAJ 2020;192(19):E497-505. DOI PubMed

6. Shoukat A, Wells CR, Langley JM, Singer BH, Galvani $A P$, Moghadas SM. Projecting demand for critical care beds during COVID-19 outbreaks in Canada. CMAJ 2020;192(19):E489-96. DOI PubMed

7. Barrett K, Khan YA, Mac S, Ximenes R, Naimark DM, Sander B. Estimation of COVID-19-induced depletion of hospital resources in Ontario, Canada. CMAJ 2020;192(24):E640-6. DOI PubMed

8. Government of Alberta. COVID-19 info for Albertans. Edmonton (AB): Government of Alberta; 2020.

https://www.alberta.ca/coronavirus-info-for-albertans.aspx

9. Saskatchewan Health Authority. SHA's Health System Readiness for COVID-19. Status Update. Regina (SK): Government of Saskatchewan; 2020. https://www. saskhealthauthority.ca/news/stories/Pages/2020/April/SHA\% E2\%80\%99s-Health-System-Readiness.aspx

10. BC Centres for Disease Control. COVID-19: Where we are. Considerations for next steps. Vancouver (BC): Government of British Columbia; 2020. https://news.gov.bc.ca/files/ COVID19_Update_Modelling-DIGITAL.pdf

11. Government of Quebec. COVID-19 Potential Scenarios, April 13, 2020. Quebec (QC): Government of Quebec; 2020. https://cdn-contenu.quebec.ca/cdn-contenu/ sante/documents/Problemes_de_sante/covid-19/COVID_ potential_scenarios.pdf
12. Government of Ontario. COVID-19 Modelling. Toronto (ON): Government of Ontario; 2020. https:// news.ontario.ca/en/release/56559/ontario-provide s-full-transparency-by-releasing-covid-19-modelling

13. Guan WJ, Ni ZY, Hu Y, Liang WH, Ou CQ, He JX, Liu L, Shan H, Lei CL, Hui DS, Du B, Li LJ, Zeng G, Yuen KY, Chen RC, Tang CL, Wang T, Chen PY, Xiang J, Li SY, Wang JL, Liang ZJ, Peng YX, Wei L, Liu Y, Hu YH, Peng $P$, Wang JM, Liu JY, Chen Z, Li G, Zheng ZJ, Qiu SQ, Luo J, Ye CJ, Zhu SY, Zhong NS; China Medical Treatment Expert Group for Covid-19. Clinical Characteristics of Coronavirus Disease 2019 in China. N Engl J Med 2020;382(18):1708-20. DOI PubMed

14. Zhao ZY, Zhu YZ, Xu JW, Hu SX, Hu QQ, Lei Z, Rui J, Liu XC, Wang $Y$, Yang $M$, Luo L, Yu SS, Li J, Liu RY, Xie F, Su YY, Chiang YC, Zhao BH, Cui JA, Yin L, Su YH, Zhao QL, Gao LD, Chen TM. A five-compartment model of age-specific transmissibility of SARS-CoV-2. Infect Dis Poverty 2020;9(1):117. DOI PubMed

15. Davies NG, Klepac P, Liu Y, Prem K, Jit M, Eggo RM; CMMID COVID-19 working group. Age-dependent effects in the transmission and control of COVID-19 epidemics. Nat Med 2020;26(8):1205-11. DOI PubMed

16. Public Health Agency of Canada. COVID-19 in Canada: Using data and modelling to inform public health action. Ottawa: 2020. https://www.canada.ca/ content/dam/phac-aspc/documents/services/ diseases/2019-novel-coronavirus-infection/ using-data-modelling-inform-eng.pdf

17. Public Health Agency of Canada. Federal/provincial/ territorial public health response plan for ongoing management of COVID-19. Ottawa; August 25, 2020. https://www.canada.ca/en/public-health/ services/diseases/2019-novel-coronavirus-infection/ guidance-documents/federal-provincial-territorial-pub lic-health-response-plan-ongoing-management-covid-19. html

18. World Health Organization. Critical preparedness, readiness and response actions for COVID-19. Geneva (Switzerland): WHO; 2020. https://www.who.int/publications/i/item/ critical-preparedness-readiness-and-response-actions- $f$ or-covid-19

19. Prem K, Cook AR, Jit M. Projecting social contact matrices in 152 countries using contact surveys and demographic data. PLOS Comput Biol 2017;13(9):e1005697. DOI PubMed

20. Statistics Canada. Quarterly Demographic Estimates, October to December 2019. Ottawa (ON): StatCan (accessed 2020-05-13). https://www150.statcan.gc.ca/n1/ pub/91-002-x/91-002-x2019004-eng.htm

21. Public Health Agency of Canada. Coronavirus disease 2019 (COVID-19) Daily Epidemiology Report June 15, 2020. Ottawa (ON): PHAC; 2020. https://health-infobase.canada. ca/covid-19/epidemiological-summary-covid-19-cases.html 
22. Kissler SM, Tedijanto C, Goldstein E, Grad YH, Lipsitch M. Projecting the transmission dynamics of SARS-CoV-2 through the postpandemic period. Science 2020;368(6493):860-8. DOI PubMed

23. Papachristodoulou E, Kakoullis L, Parperis K, Panos G. Long-term and herd immunity against SARS-CoV-2: implications from current and past knowledge. Pathog Dis 2020;78(3):25. DOI PubMed

24. World Health Organization. "Immunity passports" in the context of COVID-19 (accessed 2020-07-10). https://www. who.int/news-room/commentaries/detail/immunity-passport s-in-the-context-of-covid-19

25. Keeling MJ, Gilligan CA. Bubonic plague: a metapopulation model of a zoonosis. Proc R Soc London Ser B Biol Sci. 2000;267(1458):2219-30. DOI

26. Ogden $\mathrm{NH}$, Fazil A, Arino J, Berthiaume $P$, Fisman DN, Greer AL, Ludwig A, Ng V, Tuite AR, Turgeon P, Waddell LA, $\mathrm{Wu}$ J. Modelling scenarios of the epidemic of COVID-19 in Canada. Can Commun Dis Rep 2020;46(8):198-204. DOI PubMed

27. Tang B, Scarabel F, Bragazzi NL, McCarthy Z, Glazer M, Xiao Y, Heffernan JM, Asgary A, Ogden NH, Wu J. De-Escalation by Reversing the Escalation with a Stronger Synergistic Package of Contact Tracing, Quarantine, Isolation and Personal Protection: Feasibility of Preventing a COVID-19 Rebound in Ontario, Canada, as a Case Study. Biology (Basel) 2020;9(5):100. DOI PubMed

28. Wu J, Tang B, Bragazzi NL, Nah K, McCarthy Z. Quantifying the role of social distancing, personal protection and case detection in mitigating COVID-19 outbreak in Ontario, Canada. J Math Ind 2020;10(1):15. DOI PubMed

29. Mishra S, Kwong JC, Chan AK, Baral SD. Understanding heterogeneity to inform the public health response to COVID-19 in Canada. CMAJ 2020;192(25):E684-5. DOI PubMed

30. Banatvala J. COVID-19 testing delays and pathology services in the UK. Lancet 2020;395(10240):1831. DOl PubMed

31. Perencevich EN, Diekema DJ, Edmond MB. Moving Personal Protective Equipment Into the Community: Face Shields and Containment of COVID-19. JAMA 2020;323(22):2252-3. DOI PubMed

32. Statistics Canada. Population estimates for July 1 , by age group and sex. Table: 17-10-0005-01 Ottawa (ON): StatCan; 2020 (accessed 2020-05-13). https://www150.statcan.gc.ca/ t1/tbl1/en/tv.action?pid=1710000501

33. Stilianakis NI, Drossinos Y. Dynamics of infectious disease transmission by inhalable respiratory droplets. J R Soc Interface 2010 Sep;7(50):1355-66. DOI PubMed
34. Li L, Yang Z, Dang Z, Meng C, Huang J, Meng H, Wang $D$, Chen $G$, Zhang J, Peng $H$, Shao Y. Propagation analysis and prediction of the COVID-19. Infect Dis Model 2020;5:282-92. DOI PubMed

35. He X, Lau EHY, Wu P, Deng $X$, Wang J, Hao X, Lau YC, Wong JY, Guan Y, Tan X, Mo X, Chen Y, Liao B, Chen W, Liao B, Weilie C, Hu F, Zhang Q, Zhong M, Wu Y, Zhao L, Zhang F, Cowling BJ, Li F, Leung GM. Temporal dynamics in viral shedding and transmissibility of COVID-19. Nat Med 2020;26(5):672-5. DOI PubMed

36. Wölfel R, Corman VM, Guggemos W, Seilmaier M, Zange S, Muller MA, Niemeyer D, Jones TC, Vollmar P, Rothe C, Hoelscher M, Bleicker T, Brunink S, Schneider J, Ehmann $\mathrm{R}$, Zwirglmaier K, Drosten C, Wendtner C. Virological assessment of hospitalized patients with COVID-2019. https://www.nature.com/articles/s41586-020-2196-x

37. Khalili M, Karamouzian M, Nasiri N, Javadi S, Mirzazadeh A, Sharifi H. Epidemiological characteristics of COVID-19: a systematic review and meta-analysis. Epidemiol Infect 2020;148:e130-130. DOl PubMed

38. Mitra AR, Fergusson NA, Lloyd-Smith $E$, Wormsbecker A, Foster D, Karpov A, Crowe S, Haljan G, Chittock DR, Kanji HD, Sekhon MS, Griesdale DE. Baseline characteristics and outcomes of patients with COVID-19 admitted to intensive care units in Vancouver, Canada: a case series. CMAJ 2020;192(26):E694-701. DOI PubMed

39. Rees EM, Nightingale ES, Jafari Y, Waterlow NR, Clifford $S$, B Pearson CA, Group CW, Jombart T, Procter SR, Knight GM. COVID-19 length of hospital stay: a systematic review and data synthesis. BMC Med 2020;18(1):270. DOI PubMed

40. Argenziano MG, Bruce SL, Slater $C L$, Tiao JR, Baldwin MR, Barr RG, Chang BP, Chau KH, Choi JJ, Gavin N, Goyal P, Mills AM, Patel AA, Romney MS, Safford MM, Schluger NW, Sengupta S, Sobieszczyk ME, Zucker JE, Asadourian PA, Bell FM, Boyd R, Cohen MF, Colquhoun MI, Colville LA, de Jonge JH, Dershowitz LB, Dey SA, Eiseman KA, Girvin ZP, Goni DT, Harb AA, Herzik N, Householder S, Karaaslan LE, Lee $H$, Lieberman E, Ling A, Lu R, Shou AY, Sisti AC, Snow ZE, Sperring CP, Xiong Y, Zhou HW, Natarajan K, Hripcsak G, Chen R. Characterization and clinical course of 1000 patients with coronavirus disease 2019 in New York: retrospective case series. BMJ 2020;369:m1996. DOI PubMed 


\section{Appendix A: Model flow, compartment definitions, parameter definitions and values}

\section{Model flow}

Broadly, the naïve individuals (the Susceptible state), enter the latent infection state either in quarantine (state Lq) or while part of the general population (L). After the latent period, the individuals become infectious without developing symptomsfor individuals who will develop symptoms, this corresponds to a presymptomatic state (states lq_pres or I_pres depending on whether the individual is quarantined or not). For individuals who will remain asymptomatic, the state we call presymptomatic simply corresponds to the first phase of their infectious period, until they may be detected, or not. Individuals are then either detected (a fraction of mild symptomatic individuals, asymptomatic individuals and all with severe symptoms) or not (most of the asymptomatic and a fraction of the mild symptomatic). Detected individual with mild symptoms or who are asymptomatic are isolated at home, while detected individuals with more severe symptoms enter the hospitalization section of the model. Undetected individuals, either with mild symptoms or who are completely asymptomatic are not isolated and are considered to continue to contribute to the epidemic for as long as their infectious period, at which point they recover. Once in the hospital states, depending on severity, individuals move to one of three possible compartments: a general non-emergency ward, an intensive care unit (ICU) if they are a severe case, or an ICU unit with ventilation for the most critical patients. The model accounts for lack of care for severe cases in the situation where hospital capacity is overwhelmed. Each severe case can either die or recover. State definitions can be found in Table S1.

\section{Table S1: Model compartment definitions and values}

\begin{tabular}{|l|l|l|}
\hline State & \multicolumn{1}{|c|}{ Definitions } & \multicolumn{1}{|c|}{ Initial values } \\
\hline & & Stratification by \\
& & age group, StatCan \\
& Population estimates \\
& & July 1,2019 (32) \\
& & Ages $0-10$ estimate of \\
& & $3,982,527$ \\
& & Ages $10-20$ estimate of \\
S & Susceptible & $4,146,397$ \\
& & Ages $20-40$ estimate of \\
& & $10,286,131$ \\
& & Ages $40-60$ estimate of \\
& & $10,069,708$ \\
& & Ages $60-75$ estimate of \\
& & $6,315,255$ \\
\hline Lq & Latent in quarantine & Ages $75+$ estimate of \\
\hline
\end{tabular}

\section{Table S1: Model compartment definitions and values}

\begin{tabular}{|c|c|c|}
\hline State & Definitions & Initial values \\
\hline L & $\begin{array}{l}\text { Latent in the general } \\
\text { population (not in quarantine) }\end{array}$ & 10 \\
\hline I_pres & $\begin{array}{l}\text { Infected presymptomatic in } \\
\text { the general population (and } \\
\text { first infectious period for } \\
\text { asymptomatic) }\end{array}$ & 20 \\
\hline lq_pres & $\begin{array}{l}\text { Infected presymptomatic in } \\
\text { quarantine (and first infectious } \\
\text { period for asymptomatic) }\end{array}$ & 0 \\
\hline land & $\begin{array}{l}\text { Infected in quarantine not } \\
\text { detected (asymptomatic or } \\
\text { mild symptom) }\end{array}$ & 0 \\
\hline Ind & $\begin{array}{l}\text { Infected non-detected } \\
\text { (asymptomatic or mild } \\
\text { symptom) in the general } \\
\text { population }\end{array}$ & 2 \\
\hline Idam & $\begin{array}{l}\text { Infectious detected } \\
\text { asymptomatic or with mild } \\
\text { symptoms in the general } \\
\text { population }\end{array}$ & 0 \\
\hline Idss & $\begin{array}{l}\text { Infected detected between } \\
\text { onset of symptoms, that are } \\
\text { severe, and going to the } \\
\text { hospital }\end{array}$ & 0 \\
\hline Iss_hosp & $\begin{array}{l}\text { Infected with severe symptoms } \\
\text { who are in hospital sorting }\end{array}$ & 0 \\
\hline H_g_OK & $\begin{array}{l}\text { Infected with severe symptoms } \\
\text { who stay at the hospital in the } \\
\text { general care service }\end{array}$ & 0 \\
\hline$\underset{\mathrm{OK}}{\mathrm{H}_{-} \mathrm{ICU}_{-}}$ & $\begin{array}{l}\text { Infected with severe symptoms } \\
\text { who stay at the hospital in ICU }\end{array}$ & 0 \\
\hline $\begin{array}{l}\text { H_vent_- } \\
\text { OK }\end{array}$ & $\begin{array}{l}\text { Infected with severe symptoms } \\
\text { who stay at the hospital with } \\
\text { ventilation }\end{array}$ & 0 \\
\hline $\begin{array}{l}\mathrm{H}_{-} \mathrm{g}_{-} \\
\text {denied }\end{array}$ & $\begin{array}{l}\text { Infected with severe symptoms } \\
\text { who are not able to access } \\
\text { hospital care because of } \\
\text { insufficient/overwhelmed local } \\
\text { capacity }\end{array}$ & 0 \\
\hline $\begin{array}{l}\mathrm{H}_{-} \mathrm{ICU} \mathrm{CU}_{-} \\
\text {denied }\end{array}$ & $\begin{array}{l}\text { Infected with severe symptoms } \\
\text { who are not able to access } \\
\text { ICU because of insufficient/ } \\
\text { overwhelmed local capacity }\end{array}$ & 0 \\
\hline $\begin{array}{l}\text { H_vent_- } \\
\text { denied }\end{array}$ & $\begin{array}{l}\text { Infected with severe symptoms } \\
\text { who are not able to access } \\
\text { ventilation because of } \\
\text { insufficient/overwhelmed local } \\
\text { capacity }\end{array}$ & 0 \\
\hline $\mathrm{R}$ & Recovered & 0 \\
\hline $\mathrm{D}$ & Dead & 0 \\
\hline
\end{tabular}


Table S2: Model parameters, definition, values and evidence

\begin{tabular}{|c|c|c|c|c|c|c|c|c|c|}
\hline $\begin{array}{l}\text { Parameter } \\
\text { name }\end{array}$ & Definition & \multicolumn{7}{|c|}{ Value } & Evidence \\
\hline beta & $\begin{array}{l}\text { Probability of transmission when } \\
\text { contact made with infectious } \\
\text { person }\end{array}$ & \multicolumn{7}{|c|}{$\begin{array}{l}\text { Ages } 0-10 \text { average value of } 0.041 \\
\text { Ages } 10-20 \text { average value of } 0.041 \\
\text { Ages } 20-40 \text { average value of } 0.041 \\
\text { Ages } 40-60 \text { average value of } 0.041 \\
\text { Ages } 60-75 \text { average value of } 0.041 \\
\text { Ages } 75+\text { average value of } 0.041\end{array}$} & $\begin{array}{l}\text { Based on Stilianakis et al. (33) } \\
\text { and adjusted using data from the } \\
\text { beginning of the epidemic (Figure } \\
2 \text { in the article) }\end{array}$ \\
\hline lambda & $\begin{array}{l}\text { Proportion of exposed to } \\
\text { detected infectious who are traced } \\
\text { and quarantined (contact tracing/ } \\
\text { quarantine) }\end{array}$ & \multicolumn{7}{|c|}{$\begin{array}{l}\text { Value of } 40 \% \text { until day } 87 \\
\text { From day } 88 \text { up to the end of the epidemic, the value } \\
\text { varied according to control scenarios }\end{array}$} & NA \\
\hline \multirow{7}{*}{$c_{g g}$} & \multirow{7}{*}{$\begin{array}{l}\text { Number of daily contacts between } \\
\text { two individuals from the general } \\
\text { population }\end{array}$} & \multicolumn{7}{|c|}{$\begin{array}{l}6 * 6 \text { matrix } \\
\text { Average value of } 12.6 \text { from day } 0 \text { to day } 40 \text { (see below) }\end{array}$} & \multirow{7}{*}{ Based on Prem et al. (19) } \\
\hline & & \begin{tabular}{|l|}
$0-10$ \\
$10-20$ \\
\end{tabular} & \begin{tabular}{|l|}
4.60 \\
1.03
\end{tabular} & $\begin{array}{l}0.89 \\
0.61\end{array}$ & $\begin{array}{l}2.59 \\
2.80\end{array}$ & $\begin{array}{l}1.38 \\
2.45\end{array}$ & \begin{tabular}{l|}
0.34 \\
0.21
\end{tabular} & $\begin{array}{ll}0.04 \\
0.03\end{array}$ & \\
\hline & & $20-40$ & 1.15 & 1.67 & 8.18 & 4.05 & 0.35 & 0.04 & \\
\hline & & $40-60$ & 1.00 & 2.17 & 4.89 & 5.83 & 0.60 & 0.07 & \\
\hline & & $60-75$ & 0.63 & 0.65 & 1.89 & 2.06 & 1.98 & 0.14 & \\
\hline & & $75+$ & 0.45 & 0.66 & 0.84 & 1.42 & 0.77 & 0.46 & \\
\hline & & \multicolumn{7}{|c|}{$\begin{array}{l}\text { Linear decrease of } 50 \% \text { from days } 41 \text { and } 47 \\
\text { Value of } 50 \% \text { below normal from day } 48 \text { until day } 87 \\
\text { From day } 88 \text { up to the end of the epidemic, the value } \\
\text { varied according to control scenarios }\end{array}$} & \\
\hline \multirow{8}{*}{$\mathrm{C}_{\mathrm{gq}}$} & \multirow{8}{*}{$\begin{array}{l}\text { Number of daily contacts between } \\
\text { an individual from the general } \\
\text { population and an individual from } \\
\text { the quarantined population }\end{array}$} & \multicolumn{7}{|c|}{$\begin{array}{l}6^{\star} 6 \text { matrix identical during all the duration of the } \\
\text { simulation }\end{array}$} & \multirow{8}{*}{$\begin{array}{l}\text { We assumed a person in } \\
\text { quarantine is in contact with a } \\
\text { maximum of one person each } \\
\text { day during his/her quarantine } \\
\text { period. The value of one was } \\
\text { then standardized according to } \\
\text { the total population size in each } \\
\text { stratum }\end{array}$} \\
\hline & & $\begin{array}{l}\text { Age } \\
\text { group }\end{array}$ & 0-10 & $10-20$ & $20-40$ & $40-60$ & $60-75$ & $75+$ & \\
\hline & & $0-10$ & 0.47 & 0.09 & 0.26 & 0.14 & 0.03 & 0.00 & \\
\hline & & $10-20$ & 0.06 & 0.61 & 0.17 & 0.15 & 0.01 & 0.00 & \\
\hline & & $20-40$ & 0.07 & 0.11 & 0.53 & 0.26 & 0.02 & 0.00 & \\
\hline & & $40-60$ & 0.07 & 0.15 & 0.34 & 0.40 & 0.04 & 0.00 & \\
\hline & & $60-75$ & 0.09 & 0.09 & 0.26 & 0.28 & 0.27 & 0.02 & \\
\hline & & $75+$ & 0.10 & 0.14 & 0.18 & 0.31 & 0.17 & 0.10 & \\
\hline 20sigma & Latent period (days) & \multicolumn{7}{|l|}{4.12 days } & Based on Li et al., 2020 (34) \\
\hline delta & $\begin{array}{l}\text { Proportion of presymptomatic } \\
\text { infectious cases that will be } \\
\text { identified (or detected) }\end{array}$ & \multicolumn{7}{|c|}{$\begin{array}{l}\text { Value of } 40 \% \text { until day } 87 \\
\text { From day } 88 \text { and to the end of the epidemic, the value } \\
\text { varied according to control scenarios }\end{array}$} & NA \\
\hline alpha & $\begin{array}{l}\text { Proportion of cases who develop } \\
\text { severe symptoms }\end{array}$ & \multicolumn{7}{|c|}{$\begin{array}{l}\text { Ages } 0-10 \text { average value of } 0.02 \\
\text { Ages } 10-20 \text { average value of } 0.02 \\
\text { Ages } 20-40 \text { average value of } 0.04 \\
\text { Ages } 40-60 \text { average value of } 0.10 \\
\text { Ages } 60-75 \text { average value of } 0.30 \\
\text { Ages } 75+\text { average value of } 0.41\end{array}$} & $\begin{array}{l}\text { Based on Public Health Agency of } \\
\text { Canada (21) }\end{array}$ \\
\hline$t_{\text {pres }}$ & $\begin{array}{l}\text { Period of time between onset } \\
\text { of infectiousness and onset of } \\
\text { symptoms in those developing } \\
\text { symptoms OR first infectious } \\
\text { period for asymptomatic }\end{array}$ & \multicolumn{7}{|l|}{2 days } & Based on He et al., 2020 (35) \\
\hline
\end{tabular}


Table S2: Model parameters, definition, values and evidence (continued)

\begin{tabular}{|c|c|c|c|}
\hline $\begin{array}{l}\text { Parameter } \\
\text { name }\end{array}$ & Definition & Value & Evidence \\
\hline$t_{s m}$ & $\begin{array}{l}\text { Period of time between onset of } \\
\text { symptoms and recovery for cases } \\
\text { with mild symptoms OR second } \\
\text { infectious period for asymptomatic }\end{array}$ & 6 days & $\begin{array}{l}\text { Based on Wölfel et al., } 2020 \text { (36) } \\
\text { and He et al., } 2020 \text { (35) }\end{array}$ \\
\hline$t_{\text {sph }}$ & $\begin{array}{l}\text { Period between symptom onset } \\
\text { for cases with severe symptoms } \\
\text { and being taken care of by the } \\
\text { health system }\end{array}$ & 3 days & Based on Khalili et al., 2020 (37) \\
\hline $\mathrm{P}_{\text {ICU }}$ & $\begin{array}{l}\text { Proportion of hospitalized cases } \\
\text { who require/access to ICU in } \\
\text { hospital }\end{array}$ & $\begin{array}{l}\text { Ages } 0-10 \text { average value of } 0.20 \\
\text { Ages } 10-20 \text { average value of } 0.35 \\
\text { Ages } 20-40 \text { average value of } 0.36 \\
\text { Ages } 40-60 \text { average value of } 0.46 \\
\text { Ages } 60-75 \text { average value of } 0.46 \\
\text { Ages } 75+\text { average value of } 0.19\end{array}$ & $\begin{array}{l}\text { Based on Public Health Agency of } \\
\text { Canada (21) }\end{array}$ \\
\hline$P_{\text {vent }}$ & $\begin{array}{l}\text { Proportion of hospitalized cases } \\
\text { who require/access to ventilation } \\
\text { (Vent) }\end{array}$ & 0 & $\begin{array}{l}\text { This will be updated in future } \\
\text { models once age-specific data } \\
\text { become available }\end{array}$ \\
\hline$t_{\text {sorting }}$ & $\begin{array}{l}\text { Period of time for sorting severe } \\
\text { cases in hospital (before general } \\
\text { service, ICU or Vent) }\end{array}$ & 1 day & $\begin{array}{l}\text { We assume it takes one day on } \\
\text { average between when a severe } \\
\text { case arrives in the hospital and } \\
\text { when the case is sorted to the } \\
\text { appropriate service }\end{array}$ \\
\hline$m_{g}$ & $\begin{array}{l}\text { Mortality rate for severe cases in } \\
\text { hospital that do not require ICU or } \\
\text { Vent (general) }\end{array}$ & $\begin{array}{l}\text { Ages } 0-10 \text { average value of } 0 \\
\text { Ages } 10-20 \text { average value of } 0 \\
\text { Ages } 20-40 \text { average value of } 0 \\
\text { Ages } 40-60 \text { average value of } 0.02 \\
\text { Ages } 60-75 \text { average value of } 0.14 \\
\text { Ages } 75+\text { average value of } 0.34\end{array}$ & $\begin{array}{l}\text { Based on Public Health Agency of } \\
\text { Canada (34) }\end{array}$ \\
\hline$m_{I C U}$ & $\begin{array}{l}\text { Mortality rate for severe cases } \\
\text { dying in hospital (ICU) }\end{array}$ & $\begin{array}{l}\text { Ages } 0-10 \text { average value of } 0 \\
\text { Ages } 10-20 \text { average value of } 0 \\
\text { Ages } 20-40 \text { average value of } 0.06 \\
\text { Ages } 40-60 \text { average value of } 0.15 \\
\text { Ages } 60-75 \text { average value of } 0.32 \\
\text { Ages } 75+\text { average value of } 0.57\end{array}$ & $\begin{array}{l}\text { Based on Public Health Agency of } \\
\text { Canada (34) }\end{array}$ \\
\hline$m_{\text {Vent }}$ & $\begin{array}{l}\text { Mortality rate for severe case } \\
\text { dying in hospital (Vent) }\end{array}$ & NA & $\begin{array}{l}\text { Not calibrated because this } \\
\text { parameter has no impact on the } \\
\text { results (e.g. attack rate) presented } \\
\text { in this article }\end{array}$ \\
\hline$t_{h r}$ & $\begin{array}{l}\text { Period of time between first day in } \\
\text { hospital after sorting, and recovery } \\
\text { or death }\end{array}$ & 12 days & $\begin{array}{l}\text { Based on hospitalization and } \\
\text { length of stay of COVID-19 cases } \\
(38-40)\end{array}$ \\
\hline $\mathrm{m}_{\mathrm{g}-}$ & $\begin{array}{l}\text { Mortality rate for severe cases } \\
\text { dying at home because they are } \\
\text { not able to access hospital care }\end{array}$ & NA & $\begin{array}{l}\text { Not calibrated because this } \\
\text { parameter has no impact on the } \\
\text { results (e.g. attack rate) presented } \\
\text { in this article }\end{array}$ \\
\hline $\mathrm{m}_{\mathrm{ICU}}$ & $\begin{array}{l}\text { Mortality rate for severe cases } \\
\text { dying in hospital because they are } \\
\text { not able to access ICU }\end{array}$ & NA & $\begin{array}{l}\text { Not calibrated because this } \\
\text { parameter has no impact on the } \\
\text { results (e.g. attack rate) presented } \\
\text { in this article }\end{array}$ \\
\hline
\end{tabular}

Abbreviations: ICU, intensive care unit; NA, not applicable; Vent, ventilator 


\section{Appendix B: Equations}

$\mathrm{dS} / \mathrm{dt}=-\mathrm{S}$ * beta *1/N*[(1-lambda*delta $) *\left(c_{g g}\right.$ * $($ I_pres + Ind $)$ $+c_{\text {gq }} *($ lq_pres + lqnd $\left.)\right)+$ lambda * delta $*\left(c_{g g} *(\right.$ I_pres + Ind $)+$ $c_{g q}{ }^{*}($ lq_pres + lqnd $\left.\left.)\right)\right]$

$\mathrm{dLq} / \mathrm{dt}=\mathrm{S}$ * beta *1/N* lambda * delta * $\left(\mathrm{c}_{\mathrm{gg}}\right.$ * (I_pres + Ind $)+$ $\mathrm{c}_{\mathrm{gq}}{ }^{*}($ lq_pres + lqnd $\left.)\right)-\mathrm{Lq} /$ sigma

$\mathrm{dL} / \mathrm{dt}=\mathrm{S}$ * beta *1/N* $(1-$ lambda *delta $) *\left(c_{g g}\right.$ * (I_pres + Ind $)$ $+\mathrm{c}_{\mathrm{gq}} *($ lq_pres + lqnd $\left.)\right)-\mathrm{L} /$ sigma

dlpres $/ d t=L /$ sigma - Ipres $/ t_{\text {pres }}$

dlq_pres/ $d t=$ Lq / sigma - lq_pres $/ t_{\text {pres }}$

dlqnd / dt $=$ lq_pres *(1-delta) $/ t_{\text {pres }}-$ lqnd $/ t_{\text {sm }}$

$d$ lnd $/ d t=$ Ipres * $(1-$ delta $) / t_{\text {pres }}-$ Ind $/ t_{s m}$

dldam $/ \mathrm{dt}=\left(\right.$ lq_pres + Ipres ${ }^{\star}$ delta* $^{\star} 1$ - alpha $) / t_{\text {pres }}-I d a m / t_{s m}$

$d l d s s / d t=(\text { lq_pres }+ \text { lpres })^{\star}($ delta* alpha $) / t_{\text {pres }}-I d s s / t_{\text {sph }}$

dlss_hosp $/ d t=l d s s / t_{\text {sph }}$ - Iss_hosp $/ t_{\text {sorting }}$

$d H \_g \_O K / d t=$ Iss_hosp * $\left(1-p_{\text {ICU }}-p_{\text {vent }}\right) / t_{\text {sorting }}-H_{-}$g_OK $/ t_{\text {hr }}$ $d H \_I C U \_O K / d t=I s s \_h o s p ~ * p_{I C U} / t_{\text {sorting }}-H \_I C U \_O K / t_{h r}$ $d H \_v e n t \_O K / d t=I s s \_h o s p ~ * p_{\text {vent }} / t_{\text {sorting }}-H \_v e n t \_O K / t_{h r}$

$d H \_g \_d e n i e d / d t=0$ * Iss_hosp * $\left(1-p_{\text {Icu }}-p_{\text {vent }}\right) / t_{\text {sorting }}-H_{-}$g_ denied $/ t_{h r}$ where 0 comes from the assumed infinite capacity.

$d H \_I C U \_d e n i e d / d t=0$ * Iss_hosp * $\left(p_{I C U}\right) / t_{\text {sorting }}$ -

H_ICU_denied $/ t_{h r}$ where 0 comes from the assumed infinite capacity.

$d H \_v e n t \_d e n i e d / d t=0$ * Iss_hosp * $\left(p_{\text {vent }}\right) / t_{\text {sorting }}-H_{-}$vent_ denied $/ t_{h r}$ where 0 comes from the assumed infinite capacity.

$\mathrm{dR} / \mathrm{dt}=\mathrm{Idam} / \mathrm{t}_{\mathrm{sm}}+\mathrm{Ind} / \mathrm{t}_{\mathrm{sm}}+$ lqnd $/ \mathrm{t}_{\mathrm{sm}}+\mathrm{H}_{-} \mathrm{g}$ _OK $*\left(1-\mathrm{m}_{\mathrm{g}}\right)$ $/ t_{h r}+$ H_g_denied * $\left(1-m_{g-}\right) / t_{h r}+H_{-} I C C_{-} O K *\left(1-m_{I C U}\right) / t_{h r}+$ H_ICU_denied * $\left(1-\mathrm{m}_{\mathrm{ICU}}\right) / \mathrm{t}_{\mathrm{hr}}+\mathrm{H} \_$vent_OK * $\left(1-\mathrm{m}_{\mathrm{Vent}}\right) / \mathrm{t}_{\mathrm{hr}}$

$\mathrm{dD} / \mathrm{dt}=\mathrm{H}$ _g_OK ${ }^{*} \mathrm{~m}_{\mathrm{g}} / \mathrm{t}_{\mathrm{hr}}+\mathrm{H}$ _g_denied ${ }^{*} \mathrm{~m}_{\mathrm{g}-} / \mathrm{t}_{\mathrm{hr}}+\mathrm{H}$ _ICU_OK * $\mathrm{m}_{\mathrm{ICU}} / \mathrm{t}_{\mathrm{hr}}+\mathrm{H}$ _ICU_denied $* \mathrm{~m}_{\mathrm{ICU}-} / \mathrm{t}_{\mathrm{hr}}+\mathrm{H} \_$vent_OK $* \mathrm{~m}_{\mathrm{vent}} / \mathrm{t}_{\mathrm{hr}}$ + H_vent_denied / $t_{h r}$ 


\section{Appendix C: Sensitivity analysis for beta}

\section{Case detection/}

isolation
0.30
Contact tracing and quarantine

0.50
0.60
0.70

0.80

Attack rate for a beta $10 \%$ higher than expected (beta=0.045)

Contact rate still reduced by $50 \%$ after day 88

\begin{tabular}{|r|r|r|r|r|r|r|}
\hline 0.30 & 59.09352 & 57.4983 & 55.78916 & 53.9561 & 51.98852 & 49.87534 \\
\hline 0.40 & 51.116 & 48.47224 & 45.58901 & 42.44803 & 39.03661 & 35.35465 \\
\hline 0.50 & 40.72402 & 36.72655 & 32.39552 & 27.80149 & 23.12042 & 18.6755 \\
\hline 0.60 & 27.68375 & 22.66857 & 17.92792 & 13.9703 & 11.07788 \\
\hline 0.70 & 14.67835 & 11.41256 & $9.222685^{\mathrm{a}}$ & $7.797606^{\mathrm{a}}$ & $6.846839^{\mathrm{a}}$ & $6.127013^{\mathrm{a}}$ \\
\hline 0.80 & $7.997407^{\mathrm{a}}$ & $6.941327^{\mathrm{a}}$ & $6.220808^{\mathrm{a}}$ & $5.706796^{\mathrm{a}}$ & $5.325164^{\mathrm{a}}$ & $5.032136^{\mathrm{a}}$ \\
\hline
\end{tabular}

Contact rate reduced by $33 \%$ after day 88

\begin{tabular}{|l|r|r|r|r|r|r|}
\hline 0.30 & 72.12056 & 71.03947 & 69.87305 & 68.6118 & 67.24506 & 65.76064 \\
\hline 0.40 & 66.84949 & 65.00664 & 62.96262 & 60.688 & 58.14878 & 55.30608 \\
\hline 0.50 & 59.74349 & 56.76575 & 53.38173 & 49.5269 & 45.13509 & 40.15337 \\
\hline 0.60 & 49.97753 & 45.37923 & 40.1135 & 34.16619 & 27.6911 & 21.21683 \\
\hline 0.70 & 36.56815 & 30.14937 & 23.41448 & 17.23498 & 12.63568 & $9.755943^{\mathrm{a}}$ \\
\hline 0.80 & 20.20915 & 14.69697 & 10.93404 & $8.667255^{\mathrm{a}}$ & $7.296874^{\mathrm{a}}$ & $6.418942^{\mathrm{a}}$ \\
\hline
\end{tabular}

Contact rate reduced by $16.7 \%$ after day 88

\begin{tabular}{|r|r|r|r|r|r|r|}
\hline 0.30 & 78.97424 & 78.18379 & 77.33041 & 76.40654 & 75.40348 & 74.31118 \\
\hline 0.40 & 75.19535 & 73.84808 & 72.34734 & 70.66763 & 68.77832 & 66.64237 \\
\hline 0.50 & 70.09167 & 67.88819 & 65.35466 & 62.42254 & 59.0075 & 55.00747 \\
\hline 0.60 & 62.96743 & 59.44347 & 55.27892 & 50.33294 & 44.45665 & 37.55202 \\
\hline 0.70 & 52.71792 & 47.23034 & 40.70934 & 33.12933 & 24.9225 & 17.4795 \\
\hline 0.80 & 37.83963 & 30.13374 & 22.10612 & 15.33652 & 11.01025
\end{tabular}

Attack rate for a beta $10 \%$ lower than expected (beta=0.037)

Contact rate still reduced by $50 \%$ after day 88

\begin{tabular}{|r|r|r|r|r|r|r|}
\hline 0.30 & 46.32687 & 44.1102 & 41.73141 & 39.17554 & 36.42638 & 33.46669 \\
\hline 0.40 & 35.37861 & 31.69369 & 27.6635 & 23.2589 & 18.45491 & 13.23975 \\
\hline 0.50 & 21.11151 & 15.51616 & $9.487262^{\mathrm{a}}$ & $4.352624^{\mathrm{a}}$ & $2.026998^{\mathrm{a}}$ & $1.268084^{\mathrm{a}}$ \\
\hline $\mathbf{0 . 6 0}$ & $4.446911^{\mathrm{a}}$ & $1.925112^{\mathrm{a}}$ & $1.178985^{\mathrm{a}}$ & $0.892557^{\mathrm{a}}$ & $0.747114^{\mathrm{a}}$ & $0.659919^{\mathrm{a}}$ \\
\hline $\mathbf{0 . 7 0}$ & $0.917685^{\mathrm{a}}$ & $0.750175^{\mathrm{a}}$ & $0.655133^{\mathrm{a}}$ & $0.594146^{\mathrm{a}}$ & $0.551763^{\mathrm{a}}$ & $0.520622^{\mathrm{a}}$ \\
\hline $\mathbf{0 . 8 0}$ & $0.594963^{\mathrm{a}}$ & $0.550296^{\mathrm{a}}$ & $0.517993^{\mathrm{a}}$ & $0.493555^{\mathrm{a}}$ & $0.474428^{\mathrm{a}}$ & $0.459053^{\mathrm{a}}$ \\
\hline
\end{tabular}

Contact rate reduced by $33 \%$ after day 88

\begin{tabular}{|c|c|c|c|c|c|c|}
\hline 0.30 & 64.06551 & 62.56878 & 60.95033 & 59.19649 & 57.29164 & 55.21801 \\
\hline 0.40 & 56.83411 & 54.26817 & 51.41448 & 48.22939 & 44.66162 & 40.65115 \\
\hline 0.50 & 47.04398 & 42.87674 & 38.12076 & 32.67411 & 26.42855 & 19.2982 \\
\hline 0.60 & 33.54144 & 27.06095 & 19.59878 & 11.19984 & $4.000164^{\mathrm{a}}$ & $1.648817^{a}$ \\
\hline 0.70 & 14.97949 & $6.498159^{a}$ & $2.127114^{\mathrm{a}}$ & $1.165722^{\mathrm{a}}$ & $0.858549^{a}$ & $0.713186^{a}$ \\
\hline 0.80 & $1.48164^{\mathrm{a}}$ & $0.962062^{\mathrm{a}}$ & $0.758895^{a}$ & $0.652422^{\mathrm{a}}$ & $0.587167^{a}$ & $0.543146^{a}$ \\
\hline \multicolumn{7}{|c|}{ Contact rate reduced by $16.7 \%$ after day 88} \\
\hline 0.30 & 73.32151 & 72.24328 & 71.07465 & 69.80463 & 68.42056 & 66.90782 \\
\hline 0.40 & 68.1969 & 66.33559 & 64.25373 & 61.91416 & 59.27188 & 56.27203 \\
\hline 0.50 & 61.2006 & 58.12787 & 54.57939 & 50.45286 & 45.61944 & 39.91796 \\
\hline 0.60 & 51.36095 & 46.40851 & 40.51931 & 33.46741 & 25.00128 & 14.98944 \\
\hline 0.70 & 37.11735 & 29.3243 & 19.98326 & $9.323668^{\mathrm{a}}$ & $2.537434^{a}$ & $1.234962^{\mathrm{a}}$ \\
\hline 0.80 & 16.33694 & $6.198483^{a}$ & $1.832707^{a}$ & $1.050737^{\mathrm{a}}$ & $0.794449^{a}$ & $0.670077^{a}$ \\
\hline
\end{tabular}

